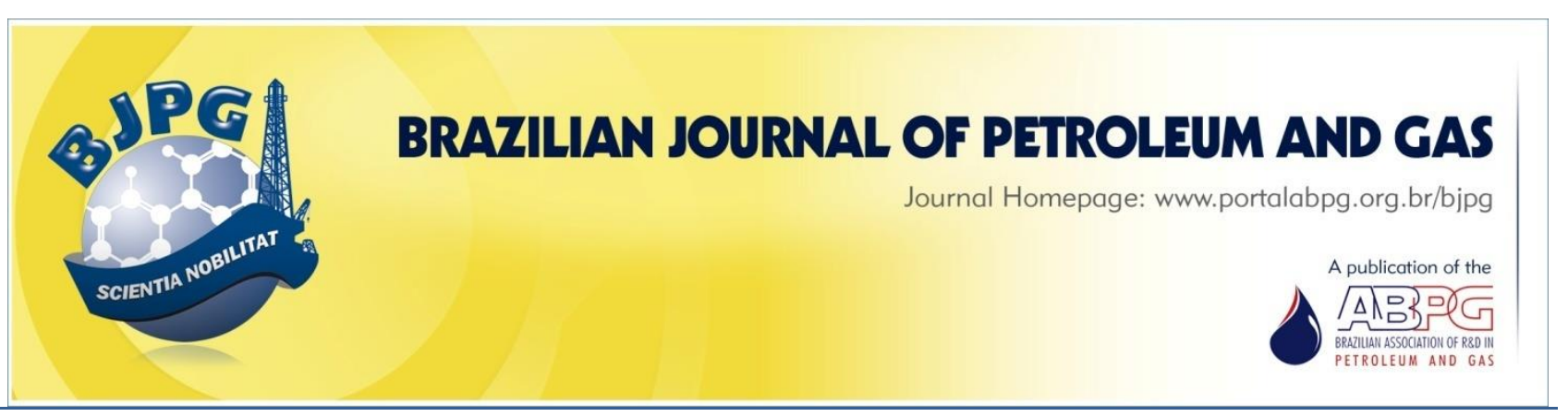

\title{
CASE STUDY: OIL SPILL USING MOHID SOFTWARE IN SÃO SEBASTIÃO - SÃO PAULO
}

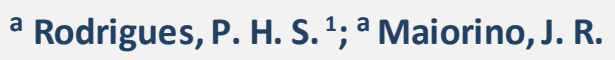 \\ a Universidade Federal do ABC, Progra ma de Pós-Graduação em Energia, Santo André-SP, Brazil \\ Received: 08.11.2016/ Revised: 06.12.2016/ Accepted: 06.12.2016 / Published on line: 29.12.2016
}

\begin{abstract}
Among the main forms of pollution generated by oil, accidents involving spill in the marine environment stand out. There is a waterway terminal in the city of São Sebastião, so oil spills are a constant proble $m$ in this location. To evaluate the impacts caused by oil spills, this work simulates some hypothetical oil spills based on the terminal waterway of São Sebastião by using a two-dimensional hydrodynamic transport model and a Lagrangian approach using MOHID software. The hydrodynamicfields were validated by real tide data and the results show how the wind direction influences oil stain trajectory. It analyzes how the issue affects many nearby locations, especially considering touristic impact, since tourism is one of most important local economic activities of the region.
\end{abstract}

\section{KEYWORDS}

oil spill, MOHID, São Sebastião, hydrodynamics

\footnotetext{
${ }^{1}$ To whom all correspondence should be a ddressed.

Address: Universidade Federal do ABC, Programa de Pós-Graduação em Energia, Ave nida dos Estados, 5001, Bangu, Santo André - SP - Brasill ZIP Code: 09210-580 | e-mail:pedro.rodrigues@aluno.ufabc.edu.br; ioserubens.maiorino@ufabc.edu.br doi:10.5419/bjpg2016-0020
} 


\section{INTRODUCTION}

Currently, one of the world's major environmental concerns is the effect caused by pollution from energy sources. Among various energy sources, oil stands out as the primary energy source used worldwide. Among the main forms of pollution generated by oil, accidents involving spill in the marine environment appear on top of the list.

There are some factors linked to oil spills such as amount and type of oil spill, the weather and oceanographic conditions, and the proximity of the accident to the coast. These factors can generate environmental impact on biota and socio-economic impacts to activities such as tourism, fishing, population health, and economy.

The most famous case of oil spill in Brazil was the rupture of the pipeline at Guanabara Bay in Rio de Janeiro. This case was responsible for the spill of more than 8,000 fuel oil barrels ( 1.30 million liters) into $50 \mathrm{~km}^{2}$ in January 2000 . Another example of catastrophic damages that is worth emphasizing is the P-36 platform wreck that happened in March 2001. The accident took place at Campos Basin in Rio de Janeiro, where between 7,500 ( 1.2 million liters) to 2,200 ( 350 thousand liters) of diesel oil barrels spilled.

The goal of this work is to present the methodology to be implemented in case of an oil spill in São Sebastião, a coastal city in the State of São Paulo, Brazil, using the MOHID software. This tool can be used in the management and control of an oil spill in that location.

\section{MATERIALS AND METHODS}

The proposed model evaluates the conditions surrounding an oil spill. First, the site's physical conditions such as bathymetry, meteorological and hydrological - temperature, wind speed and sea currents - are identified. These data is gathere d to create the velocity field simulated by the MOHID Hydrodynamic Module. This module generates and updates sea-waterflow conditions. All calculations are done using mass, momentum, and energy conservation equations for incompressible fluids and assuming hydrostatic equilibrium, which represents the balance between the strength of the vertical pressure gradient and the force of gravity. Every spatial discretization of equations is made using the finite volume technique (MARETEC; IST; UL, 2012).

MOHID has a sub-model called Lagrangian module. This is used to simulate, for example, underwater discharge, dispersion of nutrients in the water dispersion or oil after an accident. In this work, the module's objective is to calculate the spatial and temporal evolution of oil particles. So, the volume of spilled oil is divided into individual particles moving in a turbulent flow in its own coordinate system. Velocity field (generated in hydrodynamic MOHID module), wind speed, and spreading speed (generated by the oil module) influence the movement of these particles. The analysis also includes random movements.

Temporal $(t)$ and spatial $(x)$ evolution of the oil particles are calculated from the average speed definition $(u)$, given in $\mathrm{m} / \mathrm{s}$ :

$\frac{d x_{i}}{d t}=u_{i}(x, t)$,

Where,

$u_{i}=u_{1}+u_{2}+u_{3}+u_{4}$

Where, $u_{1}$ is the current velocity calculated in the hydrodynamic module; $u_{2}$ is the drift velocity due to the wind ( $3 \%$ of the wind speed $10 \mathrm{~m}$ above sea level); $u_{3}$ is the velocity component due to the oil spreading; and $u_{4}$ is the random velocity due to diffusive transport and turbulence (Janeiro et al., 2008).

The Lagrangian module needs some input data to make its calculations. Data necessary before processing includes oil type, the location and oil spill rate (or instantaneous oil spill). Figure 1 shows the algorithm used according to the methodology followed in this work, as suggested by Reed et al. (1999).

After the spill, the oil suffers some physical and chemical processes causing its disintegration and decay. These processes are influenced by the sea conditions, wind, and type of oil. Oil properties and the physical and chemical processes influencing the process are included in the MOHID Oil Module. Oil properties and degradation processes are considered to be uniform for all oil particles. 


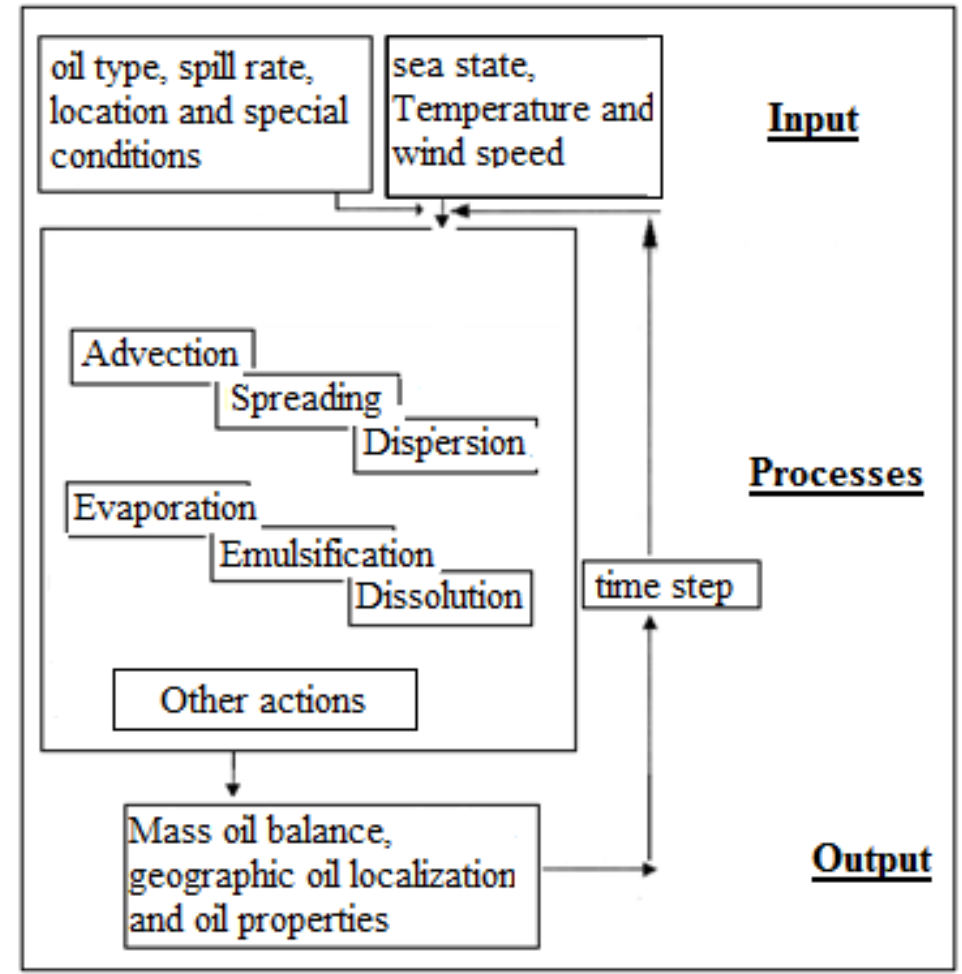

Figure 1. Algorithm used in this work.

\subsection{Processes Description}

All phenomenology involved in these processes suffer the influence of sea conditions, wind and type of oil. These factors change rates at which these processes occur and are, therefore, essential. They describe the hydrodynamic modeling, as well as the modeling of the phenomena. These processes have been developed mainly in the 1990s. Nevertheless, important updates have been observed in the areas of spreading, evaporation, dispersion, emulsification, dissolution, sedimentation, degradation (biodegradation and oxidation), and interactions with shorelines, as discussed by Reed et al. (1999) and Rodrigues (2016). This work considers these processes, with the exception of sedimentation and degradation, because they only show importance after one week of an oil spill, being considered less significant (Janeiro et al., 2008).

\subsubsection{Spreading}

In the early hours after an oil spill, spreading is one of the phenomena that most express. This process can be described as an expansion in the horizontal direction of oil stain, where the oil tends to flow over itself. The gravitational force and surface tension (Paladino, 2000) are influenced by weather and sea conditions, as well as by other processes such as evaporation and dissolution depending on the type of oil spilled.

According to Fay (1969), immediately after the oil spill, spreading occurs by gravitational forces being called the gravitational-inertia phase. After some time, this force is balanced by interfacial viscosity between oil and water, then, proceeds to a new phase of spreading called gravitationalviscous phase. When the thickness of the stain is too small, gravitational forces become negligible, and a new phase driven by the forces of surface tension starts. It is the surface tension of phase viscous - determining the end of the spread.

Thus, the only phase modeled by MOHID is the gravitational-viscous from Fay (1969) formulation (MARETEC; IST; UL, 2012). It is required to calculate spreading speed, which is used in the Lagrangian module.

The $u_{3}$ is the velocity component due spreading at the $x$ direction. It is proportional to the diffusion coefficient and is comprehended inside a fluctuation range $-U_{3} \leq 0 \leq U_{3}$, and determined by: 
$U_{3}=R_{1} \cos \left(2 \pi R_{2}\right) U_{r}$

Where $R_{1}$ is a random number between 0 and 1 . And $U_{r}$ is determined as a function of diffusion coefficient.

$U_{r}=\sqrt{\frac{2 D_{x}}{\Delta \mathrm{t}}}$.

The oil module solves the following equation proposed by Fay (1968) to the diffusion coefficient $D_{x}$.

$D_{x}=\pi \frac{k_{2}{ }^{2}}{16}\left(\frac{\rho g V_{0}{ }^{2}}{v_{w}{ }^{1 / 2}}\right)^{1 / 3} \frac{1}{\sqrt{t}}$.

Where $t$ is the time after the oil spill.

The same formulation is made to the speed component in the $y$ direction. The $u_{3}$ result, obtained by the oil module, is passed to the Lagrangian module to calculate the position of the oil particles according to Equation 1.

\subsubsection{Dispersion}

Rough sea, with waves and turbulence, break the oil stain producing several sizes of oil drops. The dispersion charge depends on the oil type and sea conditions. The formulation proposed by Mackay et al. (1980) was used to calculate the dispersion process. The dispersed mass transfer rate perhour $\left(\frac{d m_{d}}{d t}\right)$ is determined by the square of the wind speed and its unit $\mathrm{kg} / \mathrm{h}$.

$\frac{d m_{d}}{d t}=0.11 m_{\text {oil }} \frac{(1+W)^{2}}{1+50 \mu^{1 / 2} h \sigma}$,

Where $m_{\text {oil }}$ is the surface oil mass, $\mu$ is the oil dynamic viscosity (cP), $h$ is the stain thickness $(\mathrm{cm})$, and $\sigma$ is the oil-water interfacial tension (dyne/cm).

\subsubsection{Evaporation}

Evaporation is the first removal oil process to take place after an accident. It depends on the volatility of the oil spilled and it is associated with climatic conditions. Waves, strong winds, and rough sea facilitate oil evaporation, which can account up to $25 \%$ of the initial oil volume on the first day (Costa, 1999). In the evaporation process, oil stain density and viscosity increase. Water and oil emulsions form as the evaporation rate decreases.

The evaporated oil fraction is described in many studies as the evaporative exposure method, and can be formulated based on works of Fernandes (2001) and Lehr (2010), using the International System of Units as follows:

$\frac{d f_{\text {evap }}}{d t}=\frac{K_{e .} A_{s}}{V_{o}} *$

$* \exp \left[A-\frac{B}{T}\left(T_{o}-T_{g} \cdot f_{\text {evap }}\right)\right]$

Where $f_{\text {evap }}$ is the evaporated oil fraction per un it time, $K_{e}$ is the mass transfer coefficient, $A_{s}$ is the oil stain spilled area. Mackay, cited by Lehr (2010), determined empirically coefficients $A$ and $B$, which are worth 6.3 and 10.3 , respectively. $T$ is the ambient temperature, and $T_{o}$ and $T_{g}$ are correlations that depend on oil API degree to crude oil:

$T_{o}=532.98-3.1295 *(A P I)$

$T_{g}$ is the oil distillation gradient curve, which can be approximated empirically by:

$T_{g}=1356.7-247.36 *(A P I)$

The $K_{e}$ coefficient is determined by wind speed (W):

$K_{e}=2.5 * 10^{-3} * W^{0.78}$

The oil stain area $A_{s}$ expands $A_{s}$ according to:

$\frac{d A_{s}}{d t}=K_{M} A_{s}^{-1} V_{0}^{4 / 3}$

Where $K_{M}$ is a constant number, whose value is $150 \mathrm{~s}^{-1}$ (Fernandes, 2001).

\subsubsection{Emulsification}

Emulsification is a process where the oil tends to absorb water to form emulsions of water in oil, favored by moderate to intense sea conditions. Some oil types form stable emulsions called "chocolate mousse." The emulsified oil presents low degradability. The proposed Equation (12) by Mackay et al. (1980) is used widely in many models. 
$\frac{d F_{w v}}{d t}=K_{w}(1+W)^{2}\left(1-\frac{F_{w v}}{F_{w v}^{f i n a l}}\right)$

Where $F_{w v}$ is the water volume incorporated in the emulsion; $F_{w v}^{f i n a l}$ the final water volume fraction incorporated in the emulsion; $K_{w}$ is an empirical constant which has a value of $1.6 \times 10^{-6}$ (MARETEC; IST; UL, 2012).

\subsubsection{Dissolution}

A portion of the hydrocarbons may pass solution to the water column depending on various factors such as oil composition, extent of stain, water temperature, turbulence, and dispersion degree.

This phenomenon is modeled by the Cohen method and dissolution rate, given in grams per minute, and is represented by the following equation (MARETEC; IST; UL, 2012):

$$
\frac{d D i s S}{d t}=K f_{s} A_{s} S
$$

Where $f_{s}$ is the fraction of the surface covered by crude oil; $K$ is the dissolution mass transfer coefficient, which has a value of $0.01 \mathrm{~m} / \mathrm{h}$; $S$ is the solubility of the oil in the water, in $\mathrm{g} / \mathrm{cm}^{3}$. A proposal given by (Huang \& Monastero, 1982) state that, for a typical oil, the solubility can be calculated by:

$S=S_{0} e^{\alpha t}$

Where $S_{0}$ is the initial oil solubility, which has a value of $30 \mathrm{~g} / \mathrm{m}^{3}$, and $\alpha$ is a decay constant, which has a value of $0.1 ; t$ is a time after oil spin in hours.

\subsection{Study area}

In this study was considered the geographic area that includes the city of São Sebastião, located on the northern coast of São Paulo in Brazil. Surrounding São Sebastião are the cities of Caraguatatuba (north), Bertioga (south), and the island of São Sebastião (east). The latter island's territory belongs to the municipality of Ilhabela. Between the city of São Sebastião and the island, which has the same name, is the São Sebastião channel. The channel has an approximate length of $25 \mathrm{~km}$ and a width ranging from 6 to $7 \mathrm{~km}$ in the north and south entrances, respectively, narrowing up to $2 \mathrm{~km}$ in its central portion.

In the canal, there is the ferry crossing between the two cities, and the São Sebastião waterway terminal (old Almirante Barroso Terminal), the largest oil transfer terminal in the Brazil operated by Transpetro. This terminal receives oilvia tanker ships and is responsible for supplying the Cubatão refinery (RPBC), Capuava (Recap), São José dos Campos (Revap), and Paulinia (Replan) through pipelines. The local infrastructure affects the region contributing to frequent accidents.

The study conducted by Tominaga et al. (2006) evaluates the hydrodynamics of the São Sebastião channel for indirect measures, and contributes to the analysis of oil dispersion from local industry effluents. Similarly, Lamardo et al. (2013), concluded that there is a water current predominance in the northeast (NE) direction during winter, autumn, and spring. Therefore, effluent dispersions will take north and northeast direction at this period. In the summer, south west (SW) current is predominant which can influence the change in the direction of effluent dispersion.

\subsection{Data collected}

The bathymetry data was found through the nautical charts available in the Centro de Hidrografia da Marinha - CHM.

The data found in the tide gauge stations, Catálogo de Estações Maregráficas Brasileiras da Fundação de Estudos do Mar-Femar, was used to simulate the tide. This catalog provided the harmonic components that allowed the calculation obtained by the model. The calculated results can be compared with the actual data obtained by the Brazilian Navy tide board available at the Banco de Nacionalde Dados Oceanográficos-BNDO.

The meteorological and oceanographic data were obtained by the Sistema Integrado de Dados Ambientais - SINDA, from Instituto Nacional de Pesquisas Espaciais - INPE, and the Monitoring System of the Brazilian Coast - SIMCosta and Centro de Biologia Marinha - CEBIMar from the University of São Paulo - USP. However, there is no data available on the speeds of surface currents that would be needed to validate the model more accurately. 


\subsection{Calibration and validation of the $C_{R}=g \cdot n^{2} \cdot H^{-\frac{1}{3}}$ hydrodynamic model}

After collecting data and performing simulations, it is necessary to calibrate and validate the results. The hydrodynamic model of the calibration process is performed comparing the results generated by MOHID with field measurement data found. This process is essential to give greater reliability modeling (Baptistelli, 2008).

The most common way to perform the calibration is based on choosing calibration parameters after a susceptibility testing. Those parameters may be, among others, water column roughness bottom, density, wind friction coefficient with water, oil viscosity. (Baptistelli, 2008; Janeiro et al., 2008). The test consists of changing only one of these parameters in the model at a time and, then, checking the result. If the result has any significant variation pattern previously displayed, it means that the parameter is suitable for calibration.

The most suitable calibration should be obtained by comparing the results of tide height and surface speed field generated by MOHID with data measured field. However, due to lack of data speed on the water surface of the area modeled in this work, the calibration was performed by comparing only tide height patterned with that observed in the simulation period.

After susceptibility testing, the Manning coefficient, which is proportional to the water column roughness bottom, and the drag wind force coefficient were chosen to be the calibration parameters. Manning coefficient is related to a simulation of boundary conditions. With the no slipping condition to the bottom of the water column, the shear stress in the background must be equal to zero. The results are calculated as follow, in Pascal:

$\tau=\rho_{w} \cdot C_{R} \cdot \sqrt{V_{x}^{2}+V_{y}^{2}} \cdot V_{x}$

Where $V_{x}$ and $V_{y}$ are velocities in the $\mathrm{x}$ and $\mathrm{y}$ axis, respectively, to the bottom of the water column in $\mathrm{m} / \mathrm{s} . C_{R}$ is the roughness coefficient and it was calculated as:
Where $g$ is gravitational acceleration, in $\mathrm{m} / \mathrm{s}^{2}, H$ is depth, in meters, and $n$ is the inverse of Manning coefficient, in $\mathrm{s} / \mathrm{m}^{1 / 3}$. So, the Manning coefficient is, in $\mathrm{m}^{1 / 3} / \mathrm{s}$ :

$M=\frac{1}{n}$.

Then, by changing the Manning coefficient of the model, it alters the surface roughness and, consequently, the background shear stress.

To be moving parallel to the surface of the water, the air transmits its movement by the action of shear stress. In general, one can calculate the shear stress as follows (MARETEC; IST; UL, 2012):

$\tau_{W}=\rho_{a r} C_{D} W^{2}$

Where $\tau_{W}$ is a shear tension between air and water in $\mathrm{Pa}, \rho_{a r}$ is the air density in $\mathrm{kg} / \mathrm{m}^{3}$, and $C_{D}$ is the drag air coefficient.

After susceptibility testing, the parameter chosen is set so that the results are consistent with real data. By the method of trial and error, some values for the coefficient of Manning were selected, and using statistical methods on the results of the simulation, it was possible to determine which of these selected values better represent the reality for each simulation performed using the different selected values.

To compare the calculated results with the measured ones, this work used the statistical correlation method and the Relative Mean Absolute Error-RMAE method of error estimation, which can be determined by:

$R M A E=\frac{\sum_{i=1}^{n}\left|V_{m(i)}-V_{c(i)}\right|}{\sum_{i=1}^{n} V_{m(i)}}$

Where $V_{m}$ e $V_{c}$ are measured and calculated values, respectively. The criterion to check the RMAE results is shown in Table 1 (Janeiro et al., 2008). Therefore, results lower than 0.2 enable an excellent calibration model, so, simulated hydrodynamic results are equivalent to the measured values found. 
Table 1. The RMAE method qualification.

\begin{tabular}{cc}
\hline Qualification & RMAE \\
\hline Excellent & $<0.2$ \\
Good & $0.2-0.4$ \\
Reasonable & $0.4-0.7$ \\
Poor & $0.7-1.0$ \\
Bad & $>1.0$ \\
\hline Source: Janeiro et al., 2008
\end{tabular}

Table 2. Correlation and RMAE test result for the different Manning coefficients.

\begin{tabular}{ccccc}
\hline Manning $\left(\mathbf{m}^{\mathbf{1 / 3} / \mathbf{s})}\right.$ & $\mathbf{4 0}$ & $\mathbf{2 0}$ & $\mathbf{1 0 0}$ & $\mathbf{1}$ \\
\hline Correlation & 0.987 & 0.988 & 0.987 & 0.979 \\
RMAE & 0.088 & 0.086 & 0.124 & 0.088 \\
Qualification & excellent & excellent & excellent & excellent \\
\hline
\end{tabular}

\section{RESULTS AND DISCUSSIONS}

To perform the simulation, a computational mesh 205×200 spaced cells in the horizontal direction was used (x-axis) in $150 \mathrm{~m}$ and vertical direction (y-axis) $200 \mathrm{~m}$ with time step of 15 seconds. The open frontiers model forced the tide and the wind. In Figure 2, one can observe the bathymetry of the studied region.

To perform the calibration, it was used tide, wind speed, and direction real data from September 01, 2015 to October 01, 2015. To obtain the best fit, the Manning coefficients were changed to the values $1,20,40$ and $100 \mathrm{~m}^{1 / 3} / \mathrm{s}$.

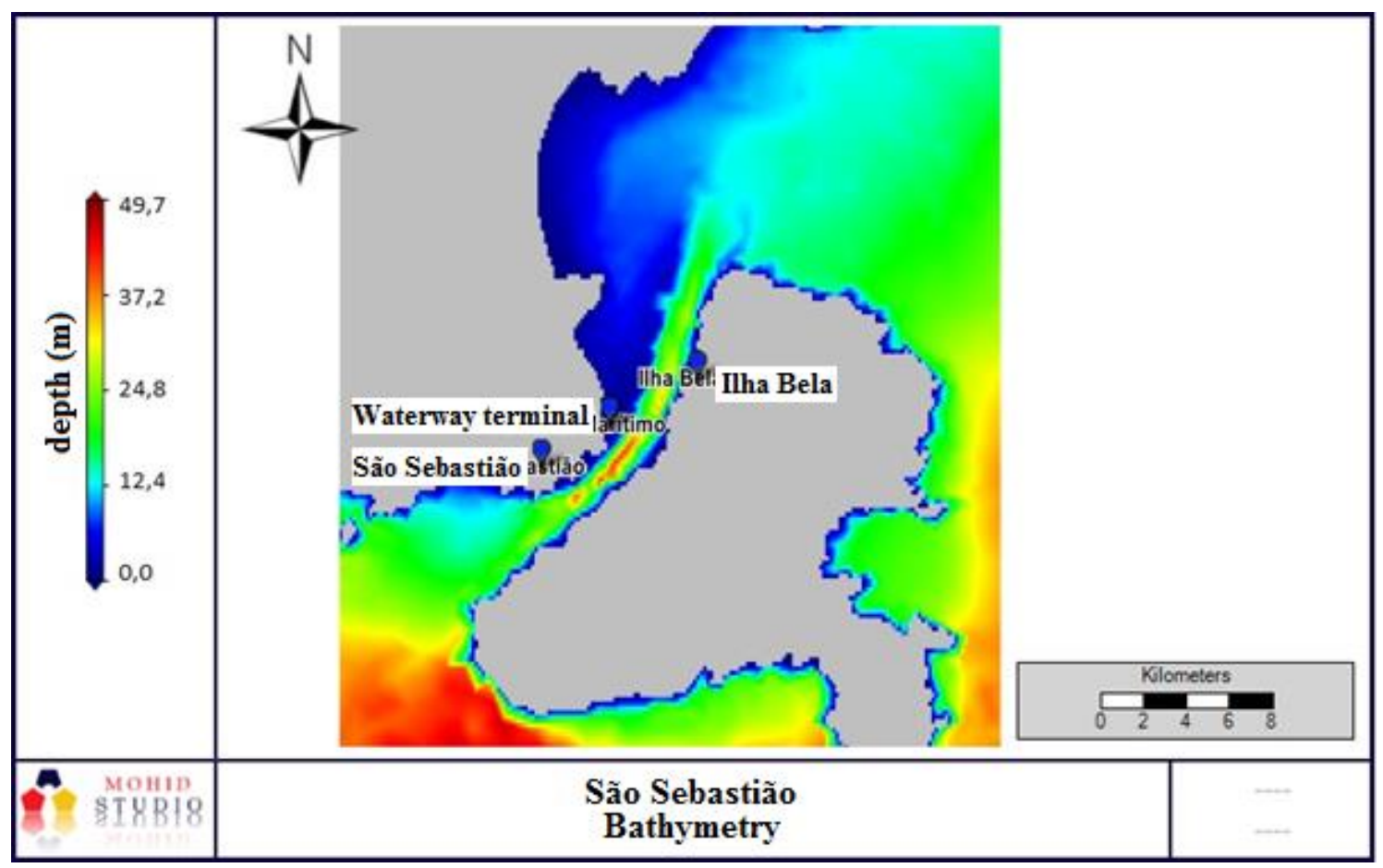

Figure 2. São Sebastião channel bathymetry. 


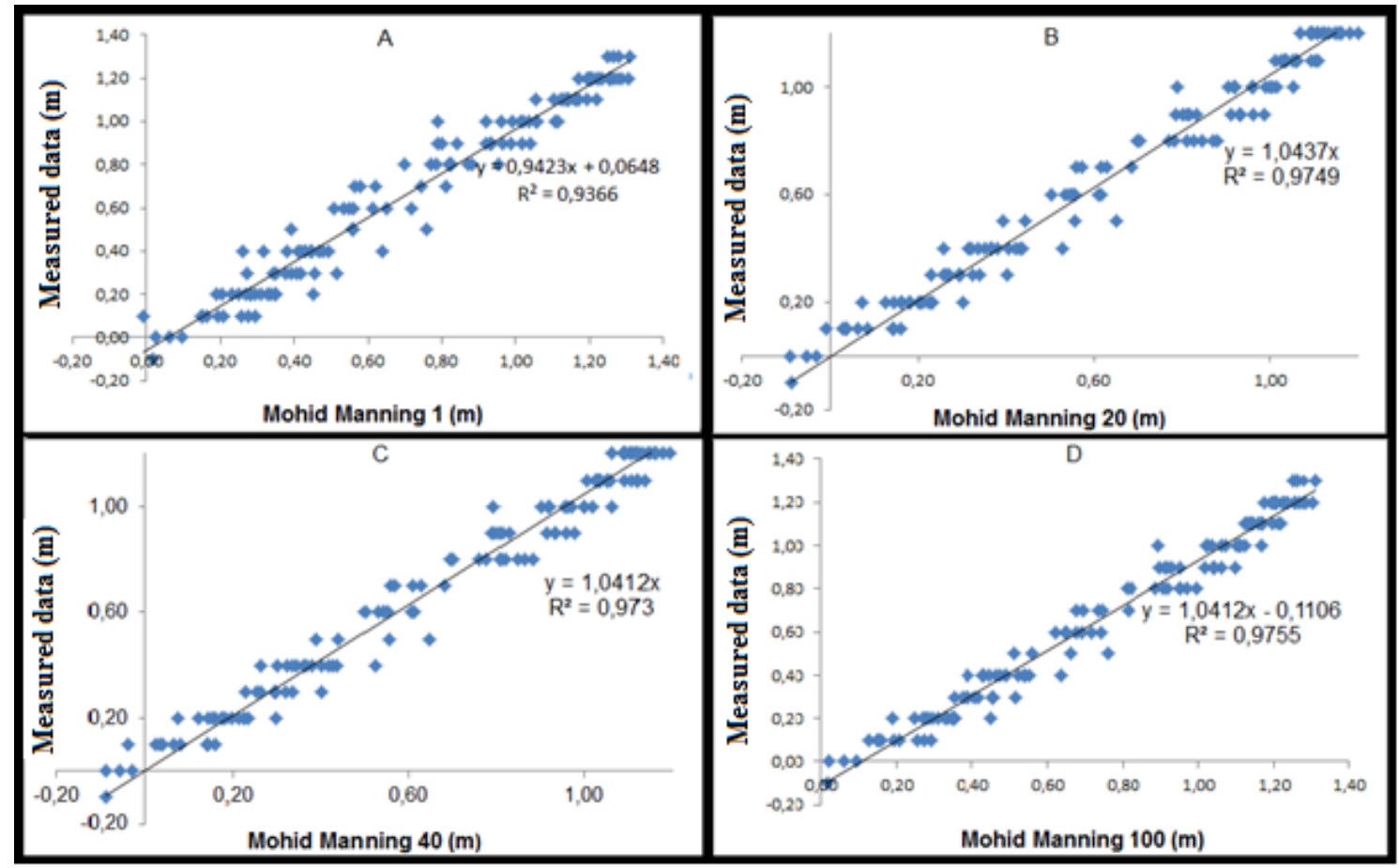

Figure 3. Correlation data between the water levels measured and calculated by MOHID for different Manning coefficients.

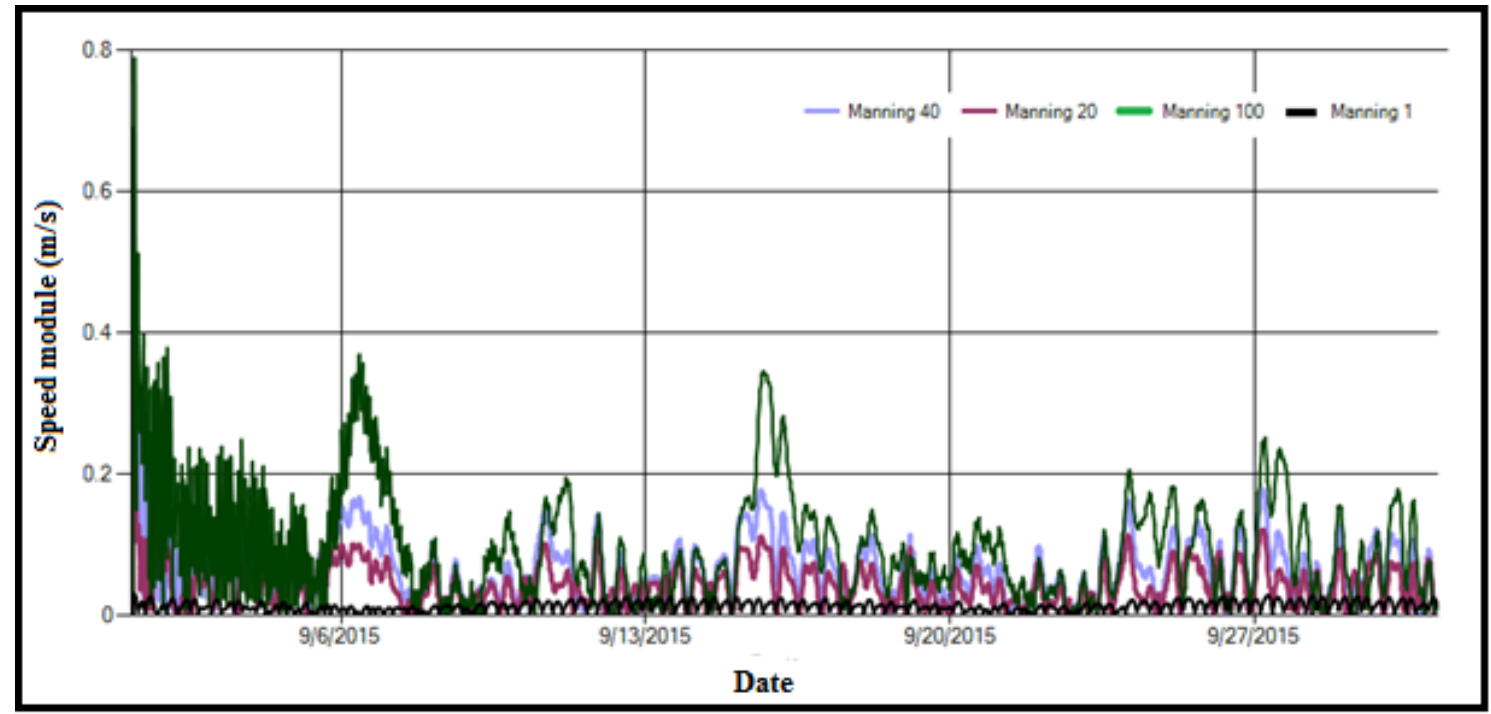

Figure 4. Water flow speed module comparison for different Manning coefficients.

Comparing the results obtained by simulation with the data available, it was specified in the model to record the water level data to the same location of where the measurement was performed. Then, a graph was plotted for each Manning coefficient, as shown in Figure 3 relating the measured data ( $y$-axis) with the data obtained in the simulation ( $x$-axis). The $R^{2}$ coefficient was used to find the best option. Table 2 shows the results to the RMAE test.
Figure 3 and Table 2 analysis show, for any chosen value, that the simulation was able to reproduce satisfactorily the reality in relation to the tidal wave. Nevertheless, different Manning coefficients generated simulations with different water velocity fields. Figure 4 shows the results for the water flow speed module for each simulated Manning coefficient. 
Table 3. Correlation and RMAE test result for different drag coefficients and the Manning coefficient equal to $20 \mathrm{~m}^{1 / 3} / \mathrm{s}$.

\begin{tabular}{cccccc}
\hline Drag Coefficient & $\mathbf{0 . 0 0 1 5}$ & $\mathbf{0 . 0 0 3 0}$ & $\mathbf{0 . 0 0 3 5}$ & $\mathbf{0 . 0 0 4 0}$ & $\mathbf{0 . 0 0 5 0}$ \\
\hline Correlation & 0.988 & 0.988 & 0.987 & 0.988 & 0.988 \\
RMAE & 0.086 & 0.087 & 0.125 & 0.087 & 0.076 \\
RMAE Qualification & Excellent & Excellent & Excellent & Excellent & excellent \\
\hline
\end{tabular}

Figure 4 shows how the Manning coefficient changes the velocity field in the simulation. One can notice that the results observed for the Manning coefficient of $1 \mathrm{~m} / / 3 / \mathrm{s}$ did not have the same patterns as the results for the other Manning values. The Manning coefficient equal to $100 \mathrm{~m}^{1 / 3} / \mathrm{s}$ resulted in higher absolute values than others, so its result was discarded. Thus, using the criterion of best RMAE and $R^{2}$, this simulation chose $20 \mathrm{~m}^{1 / 3} / \mathrm{s}$ for the Manning coefficient.

Other parameter found to calibrate the model was the drag coefficient. For this analysis, the Manning coefficient of $20 \mathrm{~m}^{1 / 3} / \mathrm{s}$ remained unchanged. Table 3 shows the selected values for the test and their RMAE values.

Based on the criteria RMAE and correlation, the drag coefficient chosen should have been 0.0050 . Nonetheless, evaluating the water current speed module at Figure, its result escapes the standards presented by other factors, so it was discarded. Then, 0.0015 drag coefficient was chosen because it presented the best value to RMAE and correlation.

Figure 5 does not show 0.0035 and 0.0040 drag coefficients, because they matched perfectly with the drag coefficient 0.0030 .

Thus, after the calibration process, the adjustment was chosen in $20 \mathrm{~m}^{1 / 3} / \mathrm{s}$ for the Manning coefficient and 0.0015 for the wind drag coefficient. In Figure 6, one can observe that the model reproduces well the water level due to the local tide.

The hypothetical accidents involving oil spills were simulated as a large spill, where volume spilled was $300 \mathrm{~m}^{3}$ of Statfjord crude oil type with characteristics shown in Table 4.

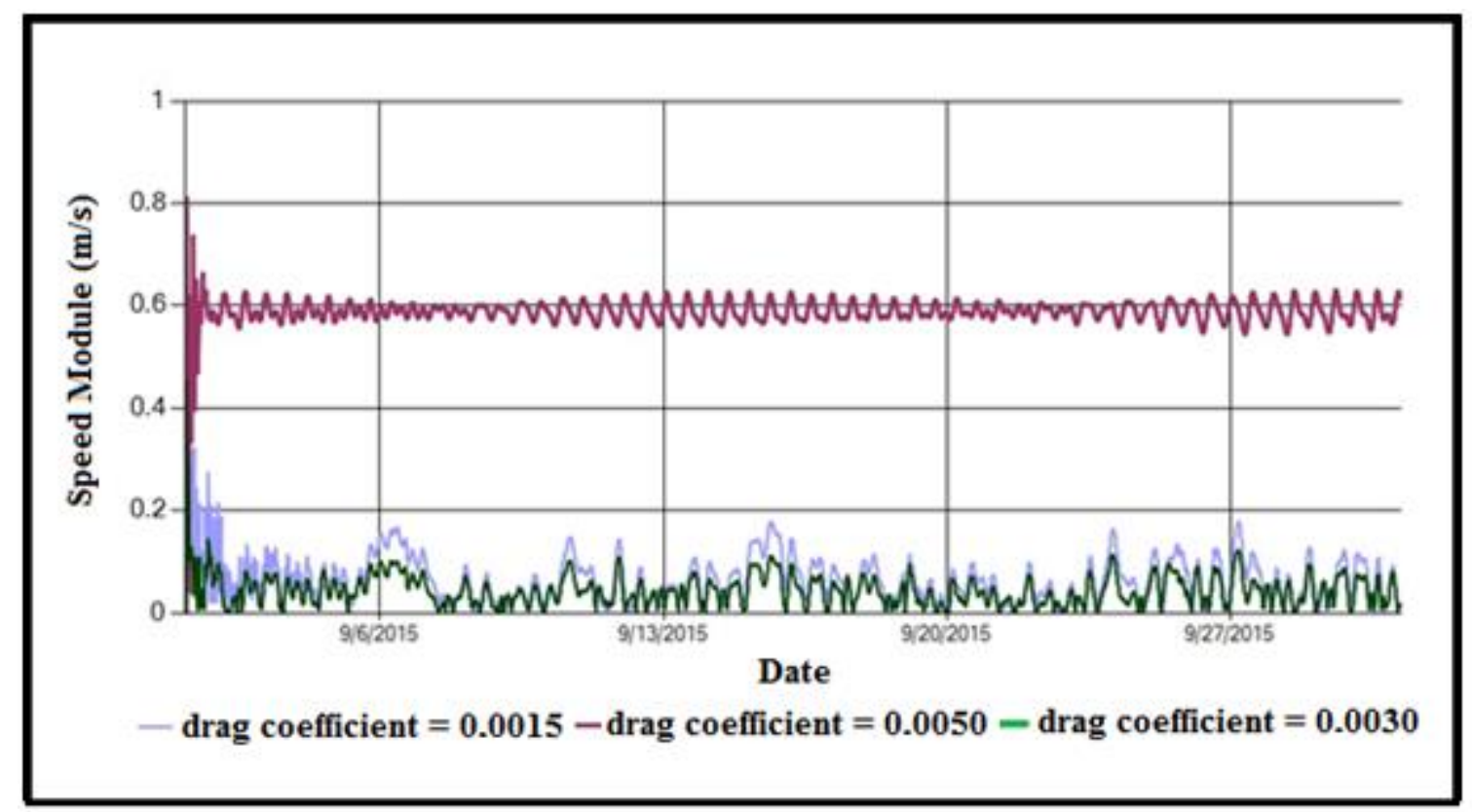

Figure 5. Water flow speed module comparison for different drag coefficients and the Manning coefficient equal to $20 \mathrm{~m}^{1 / 3} / \mathrm{s}$. 
Table 4. Statfjord crude oil characteristics.

\begin{tabular}{lc}
\hline \multicolumn{1}{c}{ Characteristics } & Values \\
\hline${ }^{\circ} \mathrm{API}$ & 37,8 \\
Pour point & $-3^{\circ} \mathrm{C}$ \\
Reference viscosity temperature & $20^{\circ} \mathrm{C}$ \\
Reference dynamic viscosity & $5 \mathrm{cP}$ \\
Interface tension between oil and water & $27.3 \mathrm{dyna} / \mathrm{cm}$ \\
\hline
\end{tabular}

Source: Janeiro et al., 2008.

The spill was instant, at 5am of September 01, 2015, at the São Sebastião waterway terminal. The simulation was made up at 5am on September 10, 2015. For this simulation, data of meteorological and oceanographic measurements available in the SIMCosta portal were used. A buoy installed in 2014 in the city of São Sebastião performed these measurements. Subsequently, these measurements were available in the portal database.

The wind direction was chosen as a parameter to evaluate the behavior of the oil stain in these hypothetical cases. For this, even when the wind module speed was ranging according to location measurement data, its direction was fixed during the entire simulation, and the results were evaluated.

Then, the simulation for two different scenarios with different wind directions was performe d: the scenario with the North wind $(\mathrm{N})$ and the scenario with Southwest wind (SW). The results for this part of the simulation are placed below.

\subsection{Temporal analysis of the oil mass and its properties}

Based on the phenomenology involved, first it was performed an analysis reducing the volume of oil due to evaporation, dispersion, and dissolution. Figure 7 shows the total oil volume at the beginning, $300 \mathrm{~m}^{3}$, and 12 hours after the spill, $175 \mathrm{~m}^{3}$. Over $40 \%$ of spilled oil volume was dissipated by the described processes. The greatest losses occur predominantly by the oil evaporation, almost $125 \mathrm{~m}^{3}$ evaporated in just 12 hours. Dispersion and dissolution were not considered significant processes for the purposes of this work.

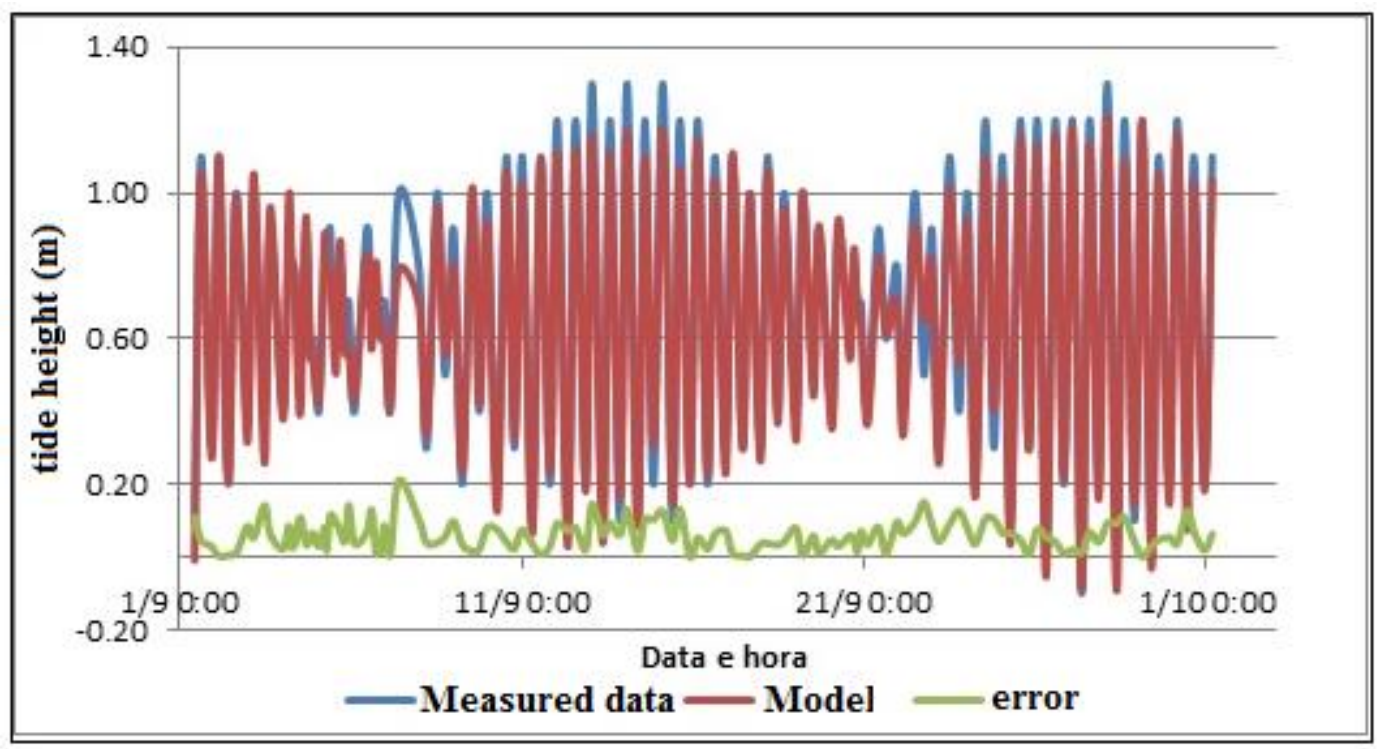

Figure 6. Comparison between simulated model tide height and the measured data in September 2015. 


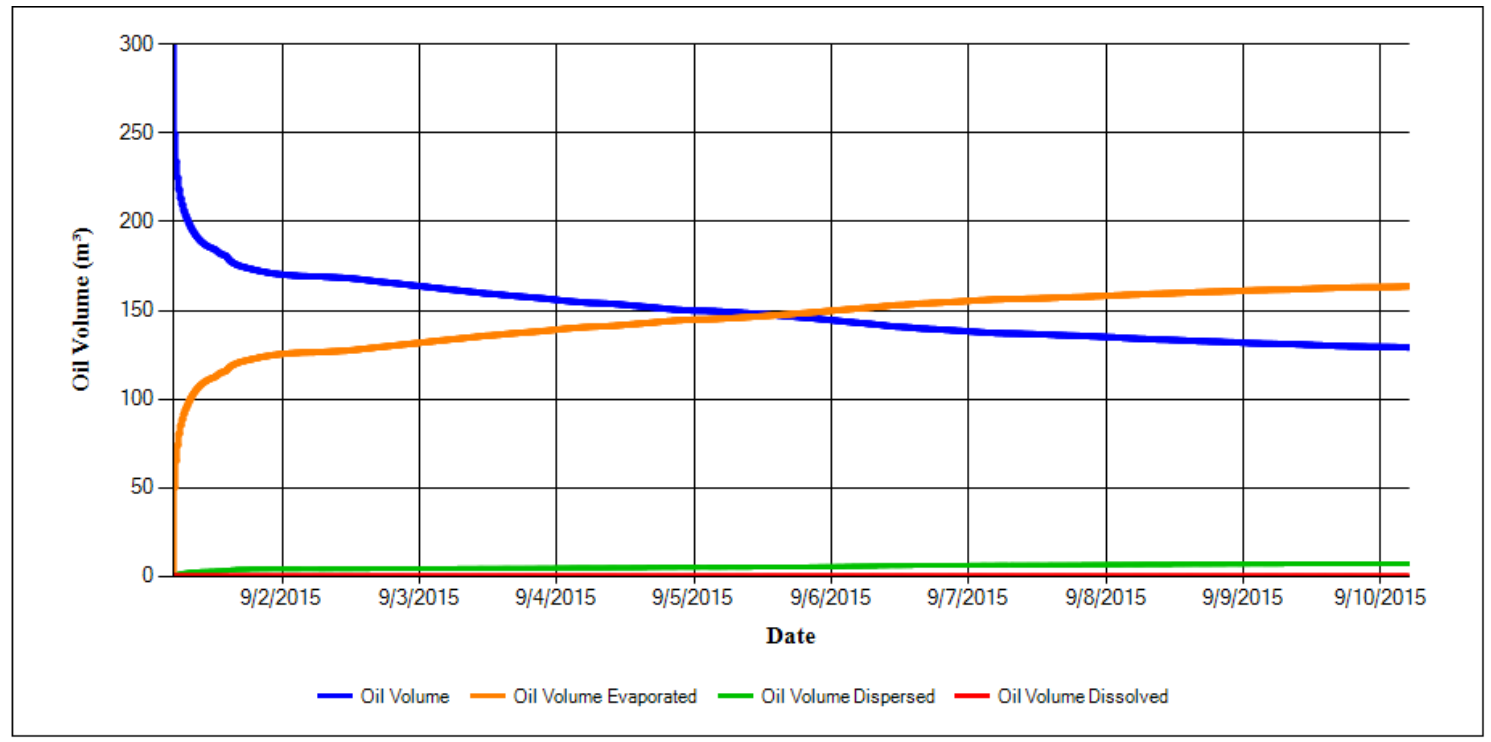

Figure 7. Oil volume temporal evolution.

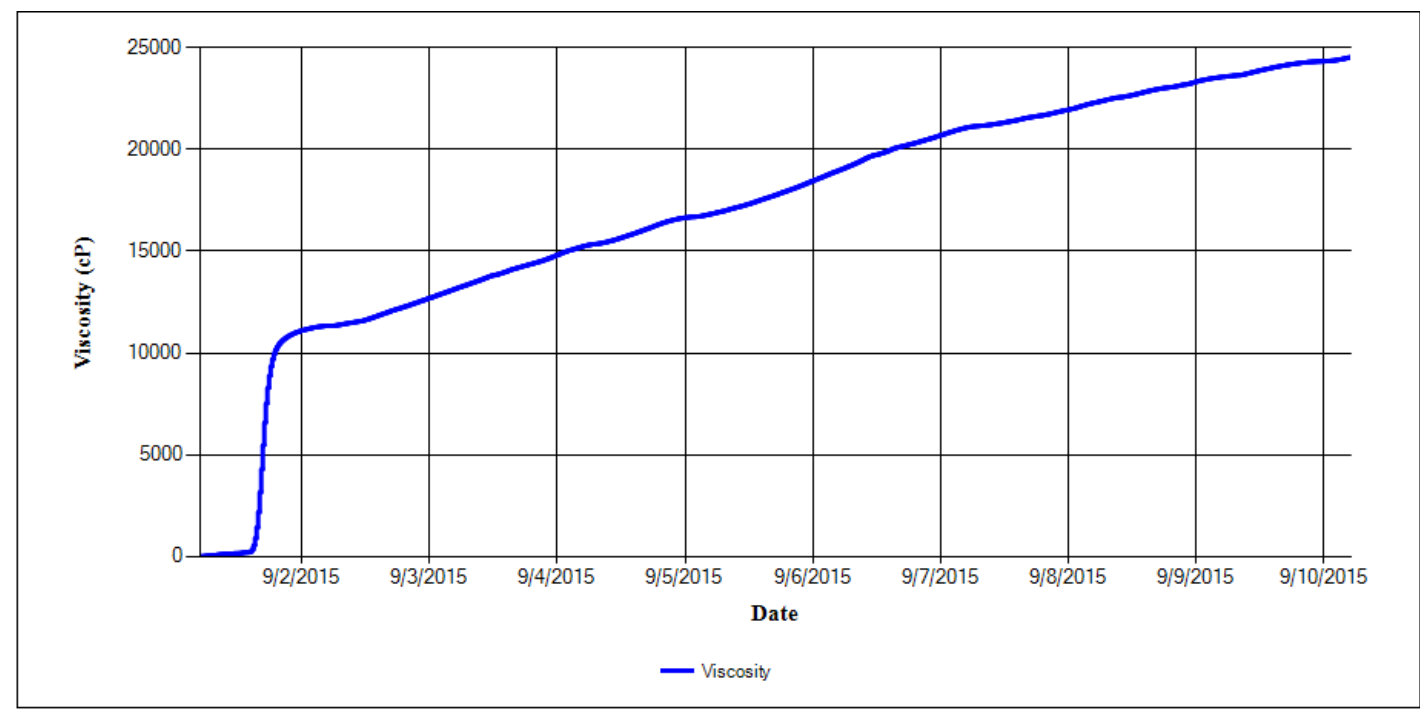

Figure 8. Oil viscosity temporal evolution.

Figure 7 shows that the evaporation rate is high in the early hours after the oil spill. After 12 hours, until the end of simulation, there is a significant reduction in evaporation rate. At this time, only 35 $\mathrm{m}^{3}$ of oil had evaporated, thus, $80 \%$ of all oil evaporated occurred within the first 12 hours of the oil spill. This occurs because emulsification and oil-land interaction reduce the oil stain area, and the rate of the oil stain area is proportional to the evaporation rate.

The dispersion practically did not occur because in a few hours the oil viscosity increased very rapidly due oil evaporation and formation of oil- water emulsions, decreasing the dispersion rate rapidly. Figure 8 shows the oil viscosity temporal evolution, and Figure 9 shows the water content in the oil-water emulsification.

The emulsification can be seen in Figure 9. After about 10 hours of the oil spill, $85 \%$ to $90 \%$ of the emulsion is water, remained stable for the next days, because this simulation did not have an external event modeled that was able to remove the emulsification, such as higher sea agitation or human action.

As a result of evaporation and formation of 


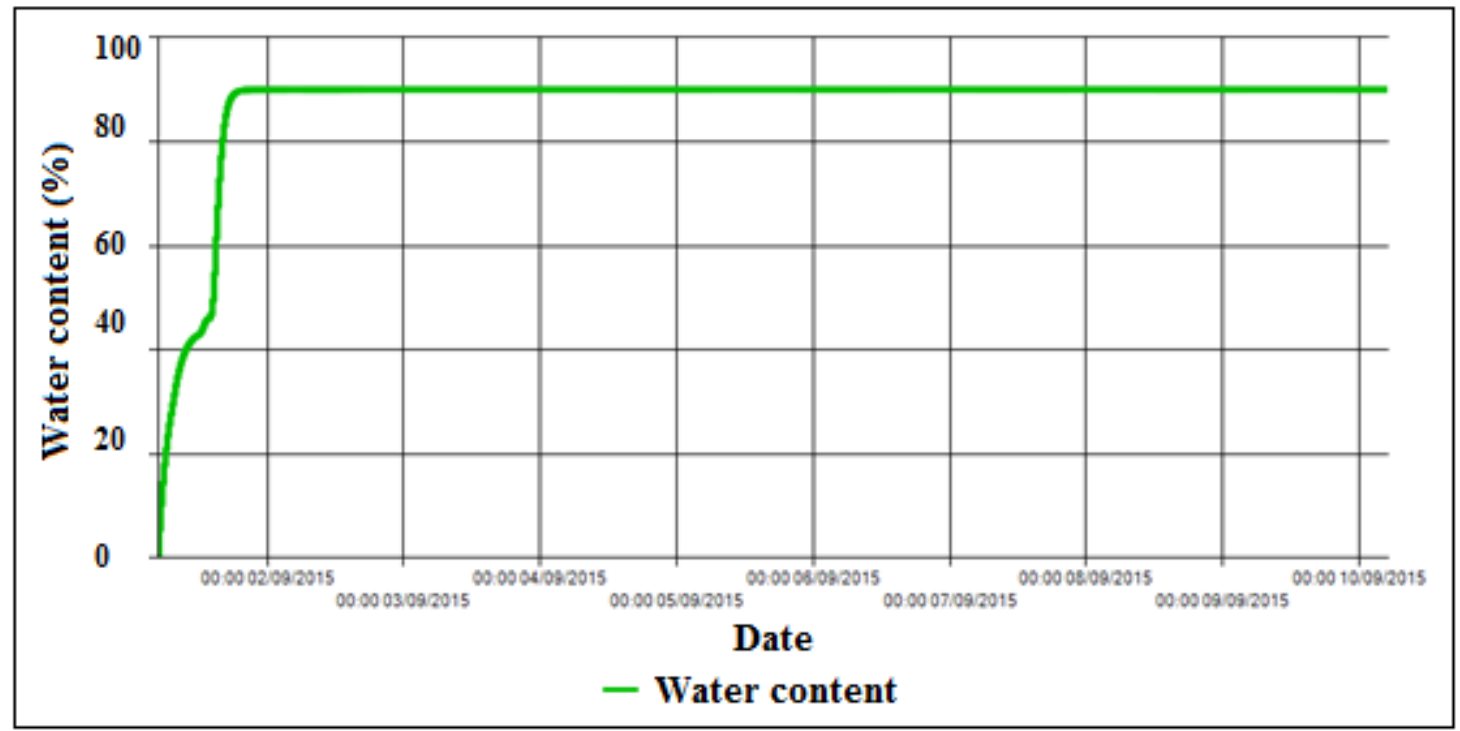

Figure 9. Water-oil content temporal evolution.

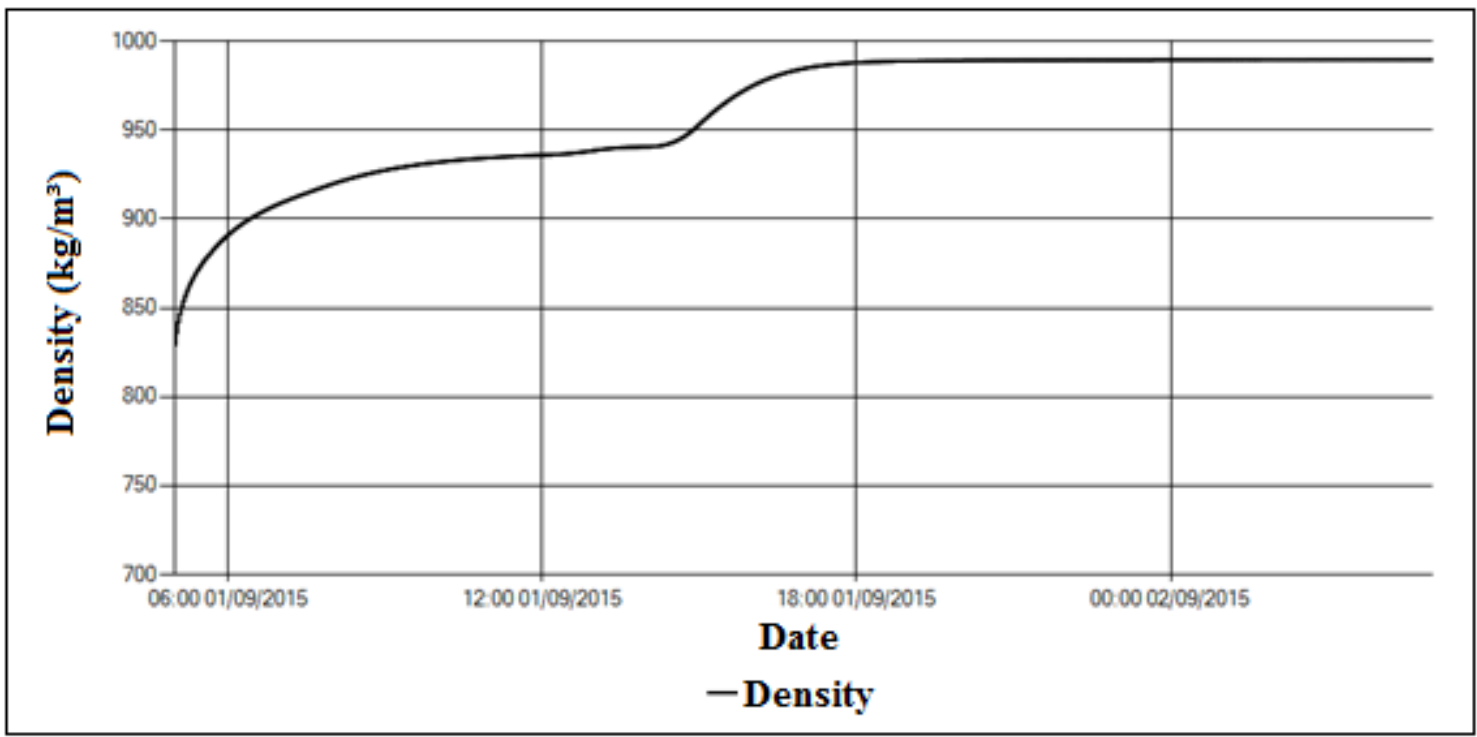

Figure 10. Oil density temporal evolution.

emulsions, the oil density increases rapidly as shown in Figure 10.

In just 12 hours, density reaches its maximum value, being near the sea water density, approximately $1000 \mathrm{~kg} / \mathrm{m}^{3}$, which makes valid the process as shown in the Mackay and Mc Auliffe (1988) work.

\subsection{0il stain temporal and spatial evolution: North Wind Scenario (N)}

Analyzing the simulation performed, in the beginning, after an hour of the oil spill, it is clear that the oil stain transport occurs in the same direction as the wind, see Figure $11(A)$. Within just five hours, the oil stain will have affected Ilhabela. If no human action is taken, after 10 days of oil contamination, practically all Il habela city southern area will be contaminated, as shown in Figure 11 (B).

3.30il stain temporal and spatial evolution: Southwest Wind Scenario (SW)

Figure 12 shows that the oil stain transport occurs in the same direction as the wind. Twelve 
A

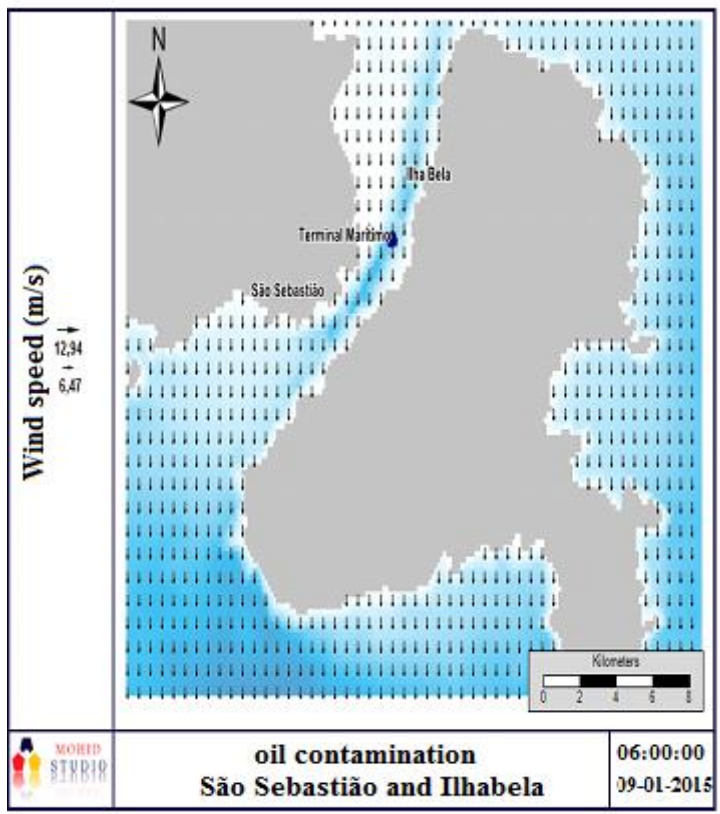

B

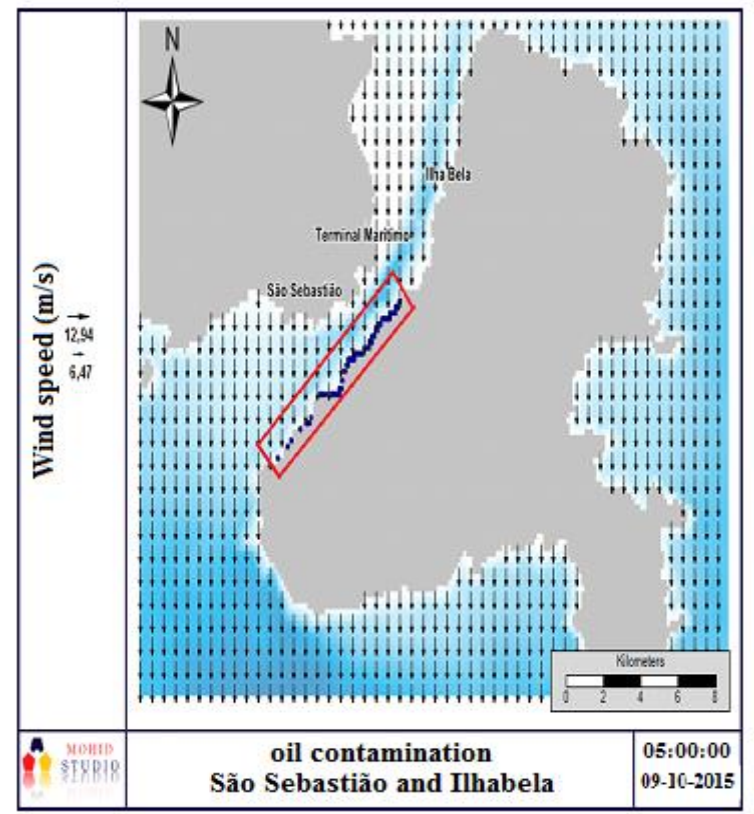

Figure 11. Oil stain temporal evolution to the North wind scenario: (A) one hour after the start of the oil spill; (B) The end of the oil stain simulation at $5 \mathrm{pm}$ on $09 / 10 / 2015$.

A

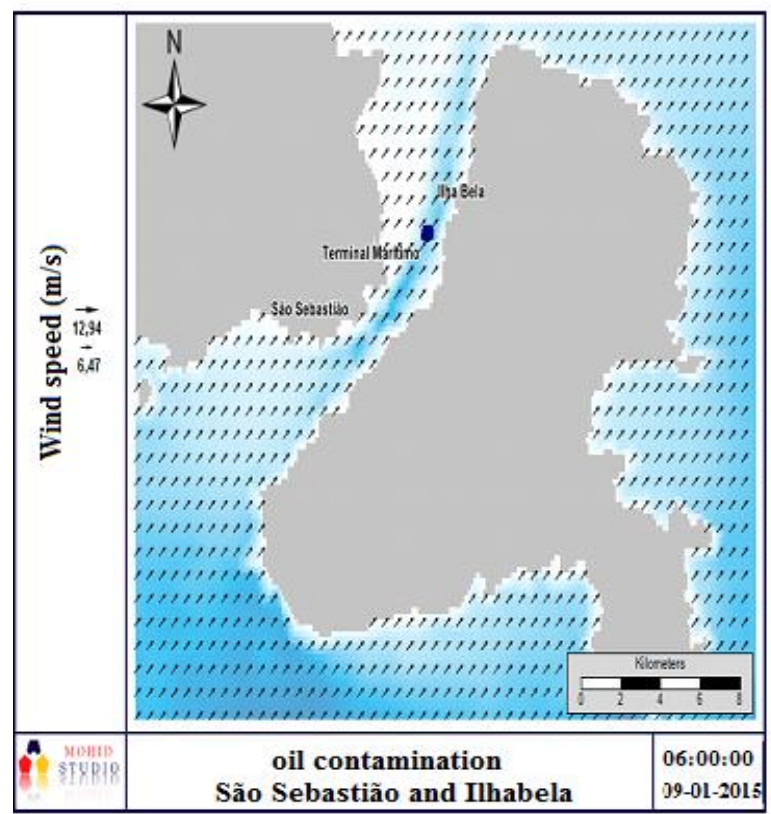

B

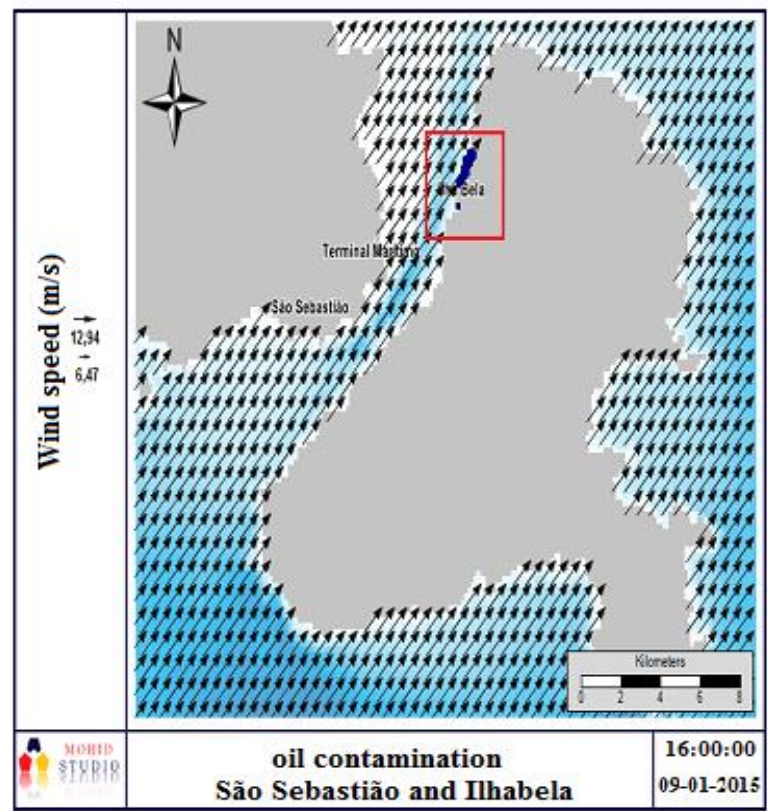

Figure 12. Oil stain temporal evolution to the Southwest wind scenario: $(A)$ one hour after the start of the oil spill; (B) Oil slick at 4 pm on 09/01/2015.

hours after the oil spill, the oil stain will have affected Ilhabela in the downtown and northern part of the city. This area of town has businesses, fishing industry, tourism, and the Yacht Country
Club. At the end of the simulation, there were no significant changes in the area contaminated by the oil. 


\section{CONCLUSIONS}

Relative calibration and tidal waves were validated by real data using the RMAE statistical criterion, classified as "excellent." The sea surface elevation due to the simulated tide showed a good reproduction of the measured levels. However, the calculations lacked the measurement of the surface water speed data, so the calibration was not validated completely by the modeled hydrodynamic.

Hypothetical simulations showed that the oil stain transport direction follows the wind direction. Analyzing the north wind scenario, one could find that the oil spill impact reaches several regions south of the ferry crossing between São Seb as tião and Ilhabela. For the Southwest wind scenario, one could observe that the oil contamination occurs downtown and in northern part of the city. In both cases, the oil reaches surrounding beaches, vacation properties, and hotels. Therefore, a potential accident would directly impact the city's economy, especially because tourism is one of the main economic activities in the region.

These scenarios do not correspond with reality, because the wind does not remain in the same direction for such a long period of time. Nevertheless, results show that, if the wind were blowing north for only five hours after the oil spill in the Waterway terminal, it would be enough time for the oil stain to reach the south of Ilhabela. In the southwest wind case, within less than six hours, it would reach the downtown Ilhabela area. In conclusion, results show there would be limited time engage in human contingency actions.

While analyzing oil properties, the results obtained proved to be in line with the ones expected. Evaporation was able to remove $40 \%$ of the oil in the early hours. Dispersion and dissolution showed to be insignificant processes in this work.

\section{ACKNOWLEDGEMENTS}

The authors would like to thank the Universidade Federal do $A B C$ (UFABC) and CAPES for the financial support.

\section{REFERENCES}

Baptistelli, S. C. Análise Crítica da Utilização de Modelagem Matemática na Avaliação da Dispersão de Efluentes Leves no Litoral da Baixada Santista (estado de São Paulo). Tese de Doutorado - Escola Politécnica da Universidade de São Paulo. São Paulo, p. 304. 2008.

https://doi.org/10.11606/t.3.2008.tde-24112008$\underline{150611}$

Costa, M. Evolução de hidrocarbonetos derramados nas zonas costeiras e estuarinas. Universidade de Coimbra. Coimbra. 1999.

Fay, J. A. The spread of oil slicks on a calm sea. Oil on The Sea, New York, p. 53-64, 1969. https://doi.org/10.1007/978-1-4684-9019-0 5

Fernandes, R. Modelação de Derrames de Hidrocarbonetos. Instituto Superior Técnico. Lisboa. 2001.

Huang, J. C.; Monastero, F. C. Review of the state-of-the-art of oil spill simulation models. Final Report submitted to the American Petroleum Institute. [S.I.]. 1982.

Janeiro, J.; Fernandes, E.; Martins, F.; Fernandes, R. Wind and freshwater influence over hydrocarbon dispersal on Patos Lagoon, Brazil. Marine Pollution Bulletin, n. 56, p. 650-665, 2008. https://doi.org/10.1016/j.marpolbul.2008.01.011

Lamardo, E. Z.; Bícego, M. C.; Weber, R. R. The fate of an oil spill in são sebastião channel: a case study. Brazilian journal of oceanography, v. 2, n. 61, p. 93-104, 2013.

Lehr, W. J. Review of modeling procedures for oil spill weathering behavior. Hazmat Division, NOAA. [S.I.]. 2010.

Mackay, D.; Bruist, I. A.; Mascarenhas, R.; Paterson, S. Oil spill processes and models. Environment Canada Manuscript Report, Ottawa, n. 8, 1980.

Mackay, D.; Mc Auliffe, C. D. Fate of Hydrocarbons Discharged at Sea. Oil \& Chemical Pollution, 5, 1988. 1-20.

https://doi.org/10.1016/S0269-8579(89)80002-4 
MARETEC; IST; UL. Descrição do MOHID. Tradução de Pedro Paulo Gomes Watts Rodrigues. Campos dos Goytacazes (RJ): Essentia, 2012. 130 p. ISBN 978-85-99968-20-8. Tradução de: MOHID Modelling System Description.

Paladino, E. Modelagem Matemática e Simulação Numérica de Trajetórias de Derrames de Petróleo no Mar. Dissertação de Mestrado Universidade Federal de Santa Catarina. Florianópolis. 2000.

Reed, M.; Johansen, O.; Brandvik, P. J.; Daling, P.; Lewis, A.; Fiocco, R.; Mackay, D.; Prentki, R. Oil spill modelling towards the close of the 20th. Spill Science \& Technology Bulletin, v. 1, p. 3-16, 1999.
Rodrigues, P. H.S. Estudo de Derramamento de Óleo Utilizando o Programa MOHID. Dissertação de Mestrado - Universidade Federal do ABC. Santo André. 2016.

Tominaga, E. N.; Rugno, N. C.; Flynn, M. N. Processos hidrodinâmicos e sedimentares avaliados na região de São Sebastião - SP. Environmental and Health World Congress, 2006. 